\title{
Perbedaan Length of Stay (LOS) Pasien Diabetes Mellitus Berdasarkan Komplikasi Di RSUP Dr. Sardjito Yogyakarta
}

\author{
Marko Ferdian Salim ${ }^{1}$, Ismil Khairi Lubis ${ }^{2}$, Sugeng ${ }^{3}$ \\ ${ }^{1,2}$ Departemen Layanan Informasi dan Kesehatan Sekolah Vokasi Universitas Gadjah Mada \\ ${ }^{3}$ Instalasi Catatan Medik RSUP Dr. Sardjito Yogyakarta \\ $\underline{\text { markoferdiansalim@ugm.ac.id }}{ }^{1}, \underline{\text { ismil.khairi@mail.ugm.ac.id }}_{2}^{2} \underline{\text { sugeng.icm } @ \text { gmail.com }}^{3}$
}

\begin{abstract}
Complications are the factors that determine the length of the day of treatment of diabetes mellitus patients in the hospital such as hypertension, stroke, coronary heart disease, cholesterol, obesity and others. This study aims to analyze differences in Length of Stay (LOS) of patients with diabetes mellitus based on complications in RSUP Dr. Sardjito Yogyakarta.This research is an analytic observational quantitative research with cross sectional design. The population is all people with diabetes mellitus from year 2011-2016 recorded in electronic medical record. All the population used as research sample that is as many as 1,554 people. Independent variables in this study were hypertension, nephropathy, neuropathy, obesity, CHD, stroke, and pulmonary TB. Dependent variable is Length of Stay or long treatment of diabetes mellitus patient. Data analysis was performed using Independent T test. Diabetes mellitus patients at RSUP Dr. Sardjito year 2011-2016 amounted to 1,554 people with a trend that tends to decline. Most patients were aged 56 - 63 years (27.86\%). The incidence of diabetes mellitus is dominated by type 2 with the highest complications being hypertension, nephropathy, and neuropathy. Based on the result of statistical test, there is a significant difference between the average LOS between patients with diabetes mellitus who have hypertension complications with non-hypertensive $(p$-value $=0.00)$, neuropathy with non-neuropathy $(p$-value $=0.00)$, coronary heart disease with which is not coronary heart disease $(p$-value $=0.035)$, and stroke with non-stroke $(p$-value $=0.032)$. Conclusions: There is significant difference in mean LOS among patients with diabetes mellitus who have complications of hypertension, neuropathy, coronary heart disease, and stroke with no complications of the disease.
\end{abstract}

Keywords: Complications, Diabetes mellitus, Length of Stay (LOS)

\begin{abstract}
Abstrak
Komplikasi merupakan faktor yang menentukan lama hari perawatan pasien diabetes mellitus di rumah sakit seperti hipertensi, stroke, penyakit jantung koroner, kolesterol, obesitas. Penelitian ini bertujuan untuk menganalisis perbedaan Length of stay (LOS) pasien diabetes mellitus berdasarkan komplikasi di RSUP Dr. Sardjito Yogyakarta. Penelitian ini merupakan penelitian kuantitatif observasional analitik dengan rancangan cross sectional. Populasinya yaitu seluruh penderita diabetes mellitus dari tahun 2011-2016 yang tercatat di rekam medis elektronik RSUP Dr. Sardjito dan besar sampelnya adalah 1.554 orang. Variabel independen dalam penelitian ini yaitu hipertensi, nephropaty, neuropati, obesitas, PJK, stroke, dan TB paru. Variabel dependen yaitu Length of Stay atau lama perawatan pasien diabetes mellitus. Analisis data dilakukan dengan menggunakan uji T Independen. Hasil penelitian menunjukkan bahwa sebagian besar pasien diabetes melitus berusia 56 - 63 tahun (27,86\%). Kejadian diabetes mellitus didominasi oleh tipe 2 dengan komplikasi tertinggi adalah hipertensi, nefropati, dan neuropati. Berdasarkan hasil uji statistik diketahui bahwa terdapat perbedaan signifikan rata-rata LOS antara pasien diabetes mellitus yang memiliki komplikasi hipertensi dengan yang tidak hipertensi ( $\mathrm{p}$-value $=0.00)$, neuropati dengan yang tidak neuropati ( $\mathrm{p}$-value $=0.00)$, penyakit jantung koroner dengan yang tidak penyakit jantung koroner ( $\mathrm{p}$-value $=0.035)$, dan stroke dengan yang tidak stroke (p-value $=0.032$ ). Simpulan penelitian ini adalah terdapat perbedaan signifikan rata-rata LOS antara pasien diabetes mellitus yang memiliki komplikasi hipertensi, neuropati, penyakit jantung koroner, dan stroke dengan yang tidak memiliki komplikasi penyakit tersebut.
\end{abstract}

Kata kunci: Diabetes mellitus, Komplikasi, Length of Stay (LOS) 


\section{Pendahuluan}

Diabetes mellitus merupakan penyakit kronis yang disebabkan oleh gangguan metabolic akibat pankreas tidak memproduksi cukup insulin atau tubuh tidak dapat menggunakan insulin yang diproduksi secara efektif seperti kekurangan dalam peningkatan konsentrasi glukosa dalam darah sehingga merusak sistem tubuh, khususnya pembuluh darah dan saraf (World Health Organization, 2017). Prevalensi diabetes mellitus terus meningkat selama beberapa dekade terakhir yang diikuti oleh prevalensi obesitas dan gaya hidup tidak sehat. Pasien dengan diabetes mellitus memiliki tingkat rawat inap tertinggi dan peningkatan risiko yang merugikan dan bahkan menyebabkan kematian (Ferreira et al., 2019).

Perkiraan dari International Diabetes Federation (IDF) terdapat 382 juta orang yang hidup dengan diabetes pada tahun 2013 dan diperkirakan akan terus meningkat sampai 592 juta pada tahun 2035. Dari 382 juta orang tersebut, 175 juta diantaranya masih belum terdiagnosis, sehingga terancam berkembang progresif menjadi komplikasi tanpa disadari dan tanpa adanya tindakan preventif. Beban penyakit tidak hanya berdasarkan peningkatan jumlah orang, tetapi juga karena peningkatan jumlah kematian dini akibat diabetes mellitus. Pada tahun 2013, setengah dari semua kematian karena Diabetes mellitus pada orang dewasa berumur di bawah usia 60 tahun (Kementrian Kesehatan RI, 2014; International Diabetes Federation, 2013).

Diabetes mellitus menjadi penyebab morbiditas dan mortalitas di negara-negara miskin dan negara berkembang yaitu sebesar $80 \%$. Diabetes mellitus menimbulkan dampak dan beban yang besar khususnya beban sosial dan ekonomi antara lain biaya pengobatan yang besar, pendapatan keluarga semakin terkuras dan mengganggu aktivitas pekerjaan. Beberapa penelitian mencoba menggambarkan dan membandingkan karakteristik pasien rawat inap diabetes dengan nondiabetes. Karena hasil riset tersebut sangat berharga bagi para profesional kesehatan, perencana perawatan kesehatan, ekonom, dan pembuat kebijakan kesehatan untuk mengatasi masalah tersebut (Donnan, Leese and Morris, 2000)

Indonesia termasuk 10 negara terbesar dengan penderita diabetes mellitus di dunia. Posisi Indonesia berada pada peringkat tujuh dengan jumlah penderita sebanyak 8.5 juta jiwa selain negara Cina 98,4 juta jiwa, India 65,1 juta jiwa, dan Amerika 24.4 juta jiwa (International Diabetes Federation, 2013).
Indonesia mengalami peningkatan prevalensi diabetes mellitus dikarenakan adanya pergeseran perubahan pola penyakit berkaitan dengan gaya hidup dari communicable disease ke arah noncomunicable disease. Setengah dari jumlah kasus diabetes mellitus tidak terdiagnosis karena pada umumnya tidak disertai gejala sampai terjadinya komplikasi. Menurut Riset Kesehatan Dasar (Riskesdas) tahun 2013, prevalensi diabetes mellitus di Indonesia berdasarkan diagnosis dokter sebesar $2,1 \%$. Prevalensi tertinggi terdapat di Sulawesi Tengah $(3,7 \%)$, Sulawesi Utara (3,6\%), Sulawesi Selatan $(3,4 \%)$ dan Nusa Tenggara Timur $(3,3 \%)$ (Kementerian Kesehatan RI, 2013).

Length of stay (LOS) merupakan indikator penting dalam menentukan keberhasilan terapi pasien diabetes mellitus. LOS juga terkait dengan biaya perawatan yang dikeluarkan pasien. Semakin sedikit waktu pasien berada di rumah sakit maka semakin efektif dan efisien pelayanan di rumah sakit. Harapan apabila seseorang dirawat di rumah sakit yaitu adanya perubahan akan derajat kesehatannya sehingga tidak perlu berlama-lama di rumah sakit.

Kualitas pelayanan rumah sakit ditentukan oleh beberapa faktor, salah satunya yaitu LOS atau lama hari perawatan. Sedangkan LOS pasien diabetes mellitus bergantung pada jenis komplikasi yang dialami. Oleh karena itu, penelitian ini bertujuan untuk melihat perbedaan LOS pasien diabetes mellitus berdasarkan jenis komplikasi.

\section{Metode Penelitian}

Penelitian ini merupakan penelitian kuantitatif observasional analitik dengan rancangan crosssectional. Populasinya yaitu seluruh penderita diabetes mellitus dari tahun 2011-2016 yang tercatat di rekam medis elektronik RSUP Dr. Sardjito. Semua populasi dijadikan sebagai sampel penelitian yaitu sebanyak 1.554 orang. Variabel independen dalam penelitian ini yaitu hipertensi, nephropaty, neuropati, obesitas, PJK, stroke, dan TB paru. Variabel dependen yaitu Length of Stay atau lama perawatan pasien diabetes mellitus. Analisis data dilakukan dengan Uji T Independen.

\section{Hasil dan Pembahasan}

Masalah kesehatan yang saat ini sedang terjadi yaitu double burden disease dimana terdapat peningkatan 
kejadian penyakit tidak menular/ degenerative yang diikuti dengan peningkatan kejadian penyakit menular. Salah satu penyakit tidak menular yang saat ini mengancam keberlangsungan hidup manusia yaitu diabetes mellitus (Notoatmodjo, 2003, 2007).

Diabetes mellitus adalah salah satu penyebab utama kematian yang disebabkan oleh karena pola makan atau nutrisi, perilaku tidak sehat, kurang aktifitas fisik dan stres. Menurut laporan Riskesdas 2007, diabetes mellitus menyumbang 4,2\% kematian pada kelompok umur 15-44 tahun di daerah perkotaan dan merupakan penyebab kematian tertinggi ke-6. Selain pada kelompok tersebut, diabetes mellitus juga merupakan penyebab kematian tertinggi ke-2 pada kelompok umur 45-54 tahun di perkotaan $(14,7 \%)$ dan tertinggi ke- 6 di daerah perdesaan $(5,8 \%)$ (Kementerian Kesehatan RI, 2012).

Diabetes mellitus merupakan penyakit kronis yang terjadi ketika pankreas tidak memproduksi cukup insulin (hormon yang mengatur gula darah) atau ketika tubuh tidak dapat secara efektif menggunakan insulin yang dihasilkannya. Insulin adalah suatu hormon yang diproduksi dalam pankreas yang memungkinkan glukosa dari makanan untuk memasuki sel-sel tubuh. Glukosa akan diubah menjadi energi yang dibutuhkan oleh otot-otot dan jaringan untuk berfungsi. Seseorang dengan diabetes mellitus tidak menyerap glukosa dengan benar, dan glukosa tetap beredar dalam darah (hiperglikemia) sehingga merusak jaringan tubuh dari waktu ke waktu. Kerusakan ini dapat menyebabkan komplikasi kesehatan (International Diabetes Federation, 2013; WHO, 2017).

Length of Stay (LOS) lama hari perawatan menunjukkan berapa hari seorang pasien dirawat pada satu episode rawat inap di fasilitas pelayanan kesehatan seperti rumah sakit, klinik, dan puskesmas. Satuan untuk LOS biasanya menggunakan hari. Kemudian cara menghitungnya yaitu dengan menghitung selisih antara tanggal pulang (tanggal keluar rumah sakit, baik dalam keadaan hidup maupun meninggal) dengan tanggal masuk rawat inap setiap pasien. Khusus pasien yang masuk dan keluar pada hari yang sama maka lama dirawat dihitung sebagai 1 hari.

LOS pasien diabetes mellitus dapat dihitung berdasarkan catatan rekam medis pasien baik secara elektronik maupun manual dengan cara menghitung selisih tanggal keluar dengan tanggal masuk. Berdasarkan data rekam medis pasien diketahui bahwa data LOS pasien diabetes mellitus seperti tabel berikut.

Tabel 1. Hasil Pengukuran LOS Pasien Diabetes Mellitus

\begin{tabular}{clc}
\hline No. & \multicolumn{1}{c}{ Pengukuran } & Hasil \\
\hline 1. & Mean & 9.93 \\
2. & Median & 8.00 \\
3. & Mode & 5.00 \\
4. & Std. Deviation & 7.77 \\
5. & Variance & 60.36 \\
6. & Range & 71 \\
7. & Minimum & 1 \\
8. & Maximum & 73 \\
\hline
\end{tabular}

Berdasarkan tabel 1 di atas diketahui bahwa ratarata LOS pasien diabetes mellitus yaitu 9.93 hari, yang paling lama yaitu 72 hari, yang paling singkat yaitu 1 hari, dan kebanyakan pasien dirawat yaitu selama 5 hari.

Pasien diabetes mellitus tipe 2 ditemukan lebih sering dan lebih lama mendapatkan perawatan di rumah sakit dibandingkan dengan pasien non-diabetes. Hal ini disebabkan oleh risiko neurologis, kardiovaskular, ginjal, dan oftalmik yang lebih tinggi dibandingkan dengan orang tanpa diabetes (Donnan, Leese and Morris, 2000).

Penyakit kaki diabetik (diabetic foot disease) pada pasien rawat inap dengan diabetes tidak hanya dikaitkan dengan peningkatan LOS tetapi juga dengan mortalitas rawat inap. Penelitian membuktikan tentang mortalitas yang tinggi akibat penyakit kaki diabetic. Penyakit kaki diabetik biasanya merupakan prekursor untuk gejala sisa yang parah seperti amputasi. Studi jangka panjang menunjukkan kualitas hidup yang buruk dan peningkatan mortalitas jangka panjang ditemukan pada pasien penyakit kaki diabetik (Nirantharakumar et al., 2013).

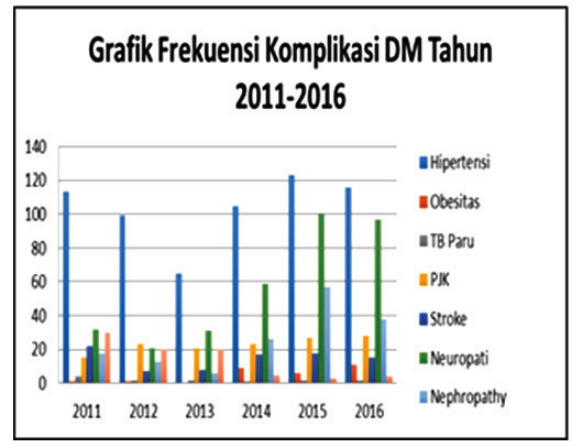

Gambar 1. Grafik Frekuensi Komplikasi Diabetes Mellitus Tahun 2011 - 2016 
Berdasarkan grafik pada gambar 1. diketahui bahwa komplikasi pasien diabetes mellitus paling tinggi dari tahun 2011-2016 yaitu hipertensi dengan jumlah kejadian paling tinggi pada tahun 2015 sebanyak 123 kejadian. Diabetes dan hipertensi sering terjadi bersamaan dimana terdapat substantial overlap antara diabetes dan hipertensi dalam etiologi dan mekanisme penyakit. Obesitas, peradangan, stres oksidatif, dan resistensi insulin dianggap sebagai common pathways (Cheung and Li, 2012).

Tabel 2. Distribusi rata-rata LOS Pasien Diabetes Mellitus Berdasarkan Komplikasi di RSUP Dr. Sardjito Yogyakarta

\begin{tabular}{llccc}
\hline No. & \multicolumn{1}{c}{ Variabel } & Mean & SD & P-Value \\
\hline 1. & Hipertensi & & & \\
& Hipertensi & 11.22 & 7.56 & 0.00 \\
& Tidak Hipertensi & 9.05 & 7.79 & \\
2. & Nephropaty & & & \\
& Nephropaty & 10.07 & 4.85 & 0.721 \\
& Tidak & 9.91 & 8.03 & \\
& Nephropaty & & & \\
3. & Neuropaty & & & \\
& Neuropaty & 14.00 & 9.72 & 0.000 \\
& Tidak Neuropaty & 8.78 & 6.69 & \\
4. & Obesitas & & & \\
& Obesitas & 12.25 & 8.15 & 0.111 \\
& Tidak Obesitas & 9.89 & 7.76 & \\
5. PJK & & & \\
& PJK & 11.26 & 7.64 & 0.035 \\
& Tidak PJK & 9.80 & 7.77 & \\
6. & Stroke & & & \\
& Stroke & 11.67 & 8.73 & 0.032 \\
Tidak Stroke & 9.82 & 7.70 & \\
7B Paru & & & \\
TB Paru & 11.14 & 11.08 & 0.557 \\
& Tidak TB Paru & 9.92 & 7.74 & \\
\hline & & & & \\
\hline & & &
\end{tabular}

Berdasarkan tabel 2 diketahui bahwa rata-rata LOS pasien diabetes mellitus yang hipertensi lebih tinggi yaitu 11.22 hari dengan variasi 7.56 hari, dibandingkan dengan LOS pasien diabetes mellitus tidak hipertensi yaitu 9.05 hari dengan variasi 7.79 hari. Hasil uji T didapatkan $p$-value $=0.000$ berarti secara statistik ada perbedaan signifikan rata-rata LOS antara pasien diabetes mellitus yang hipertensi dengan yang tidak hipertensi.
Kejadian hipertensi berhubungan dengan diabetes mellitus dimana pasien diabetes mellitus cenderung mempunyai tekanan darah yang lebih tinggi. Dengan demikian, diperlukan intervensi non-farmakologis dan farmakologis pada penderita DM untuk mencegah timbulnya komplikasi hipertensi di masa yang akan datang. Intervensi non-farmakologis yang dapat dilakukan meliputi diet rendah garam $(\leq 2,4$ gram natrium atau 6 gram $)$, olahraga secara teratur, menerapkan pola diet rendah lemak dan gula. Intervensi farmakologis yang dapat dilakukan meliputi penggunan Obat Hipoglikemik Oral (OHO) dan insulin bagi penderita DM yang memiliki indikasi (Silih, 2012).

Berdasarkan tabel 2 diketahui bahwa rata-rata LOS pasien diabetes mellitus yang nephropaty lebih tinggi yaitu 10.07 hari dengan variasi 4.85 hari, dibandingkan dengan LOS pasien diabetes mellitus tidak nephropaty yaitu 9.91 hari dengan variasi 8.03 hari. Hasil uji T didapatkan $p$-value $=0.721$ berarti secara statistik tidak ada perbedaan signifikan rata-rata LOS antara pasien diabetes mellitus yang nephropaty dengan yang tidak nephropaty.

Komplikasi yang terkait dengan diabetes mellitus telah meningkatkan jumlah kematian dalam beberapa tahun terakhir. Komplikasi ini adalah hasil dari efek jangka panjang diabetes mellitus pada mikrovaskulatur glomerular ginjal. Diabetik Nefropati (DN) berkembang pada pasien dengan riwayat medis beberapa tahun dari diabetes dan gagal ginjal.

Mortalitas pasien DN sangat tinggi. Sebagai contoh, pasien dengan diabetes tipe 1 memiliki mortalitas 20 kali lebih besar dari pada populasi umum, dan risiko relatif ini dapat diperbesar oleh 25 kali lebih lanjut untuk mereka dengan proteinuria. Mortalitas pasien DN sebagian besar merupakan hasil dari penyakit kardiovaskular komorbiditas. Sebagian besar pasien dengan stadium 4 DN meninggal sebelum mereka mencapai ESRF.

Dalam beberapa tahun terakhir telah banyak kemajuan dalam memahami faktor risiko dan mekanisme DN, tahapan keterlibatan ginjal pada diabetes, dan strategi pengobatan untuk mencegah atau mengganggu perkembangan DN. Deteksi dini DN, adopsi intervensi multifaktorial yang menargetkan faktor risiko utama (hiperglikemia, hipertensi, dislipidemia dan merokok), dan penggunaan agen dengan efek renoprotektif memang memperlambat perkembangan penyakit ginjal. Akan tetapi pengobatan hipertensi 
merupakan prioritas pada kasus diabetes mellitus. Perhatian terhadap prosedur ini juga akan memastikan pengurangan mortalitas kardiovaskular (Muhammad and Nazar, 2014).

Nefropati diabetik merupakan komplikasi kronis pada DM tipe 1 (kerusakan sel beta - kekurangan insulin absolut) dan DM tipe 2 (resistensi insulin dan/ atau penurunan sekresi insulin) (Vujičić, Turk and Crnčević-orlić, 2012).

Rata-rata LOS pasien pada tabel 2 diketahui bahwa diabetes mellitus yang neuropati lebih tinggi yaitu 14.00 hari dengan variasi 9.72 hari, dibandingkan dengan LOS pasien diabetes mellitus tidak neuropati yaitu 8.78 hari dengan variasi 6.69 hari. Hasil uji T didapatkan $p$-value $=0.000$ berarti secara statistik ada perbedaan signifikan rata-rata LOS antara pasien diabetes mellitus yang neuropati dengan yang tidak neuropati.

Neuropati diabetik adalah keluarga gangguan saraf yang disebabkan oleh diabetes. Penderita diabetes mengalami kerusakan saraf di seluruh tubuh seiring berjalan waktu. Beberapa orang dengan kerusakan saraf tidak memiliki gejala. Tetapi ada juga yang memiliki gejala seperti nyeri, kesemutan, mati rasa, kehilangan perasaan di tangan, lengan, kaki, dan kaki. Masalah saraf dapat terjadi di setiap sistem organ, termasuk saluran pencernaan, jantung, dan organ seks (NIDDK, 2009).

Sekitar 60 hingga 70 persen orang dengan diabetes memiliki beberapa bentuk neuropati. Orang dengan diabetes dapat mengembangkan masalah saraf setiap saat, tetapi risiko meningkat seiring usia dan durasi diabetes yang lebih lama. Tingkat tertinggi neuropati adalah di antara orang-orang yang menderita diabetes setidaknya selama 25 tahun. Neuropati diabetik juga tampak lebih umum pada orang yang memiliki masalah mengontrol glukosa darah mereka, juga disebut gula darah, serta mereka yang memiliki kadar lemak darah tinggi dan tekanan darah dan mereka yang kelebihan berat badan.

Penyebab dari diabetes neuropati yaitu sebagai berikut:

1. Faktor metabolik, seperti glukosa darah tinggi, durasi diabetes yang panjang, kadar lemak darah yang tidak normal, dan kemungkinan tingkat insulin yang rendah.

2. Faktor neurovaskular, yang menyebabkan kerusakan pada pembuluh darah yang membawa oksigen dan nutrisi ke saraf.
3. Faktor autoimun yang menyebabkan peradangan pada saraf.

4. Cedera mekanik pada saraf, seperti sindrom terowongan karpal.

5. Sifat yang diwariskan yang meningkatkan kerentanan terhadap penyakit saraf.

6. Faktor gaya hidup, seperti merokok atau penggunaan alkohol.

Diagnosis dini yang akurat memungkinkan untuk perawatan adekuat, mencegah perkembangan neuropati dan komplikasi berat. Dengan demikian, perlu untuk memperoleh riwayat klinis yang akurat, selain tes neurologis menyeluruh dan tes tambahan, untuk mengidentifikasi tanda-tanda keterlibatan serat saraf. Perawatannya tergantung pada kontrol glikemik yang memadai dan perawatan nyeri neuropatik (Nascimento, Pupe and Cavalcanti, 2016).

Berdasarkan tabel 2 dapat dilihat bahwa rata-rata LOS pasien diabetes mellitus yang obesitas lebih tinggi yaitu 12.25 hari dengan variasi 8.15 hari, dibandingkan dengan LOS pasien diabetes mellitus tidak obesitas yaitu 9.89 hari dengan variasi 7.76 hari. Hasil uji $\mathrm{T}$ didapatkan $\mathrm{p}$-value $=0.111$ berarti secara statistik tidak ada perbedaan signifikan rata-rata LOS antara pasien diabetes mellitus yang obesitas dengan yang tidak obesitas.

Diabetes mellitus sangat berkaitan dengan obesitas. Prevalensi obesitas penduduk $>18$ tahun di Indonesia sebesar $11,7 \%$, sebesar $7,8 \%$ pada laki-laki dan $15,5 \%$ pada perempuan.

Kegemukan dan obesitas didefinisikan sebagai akumulasi lemak abnormal atau berlebihan yang dapat mengganggu kesehatan. Indeks massa tubuh (IMT) adalah indeks sederhana berat yang biasanya digunakan untuk mengklasifikasikan kelebihan berat badan dan obesitas pada orang dewasa. Ini didefinisikan sebagai berat seseorang dalam kilogram dibagi dengan kuadrat tinggi badannya dalam meter $(\mathrm{kg} / \mathrm{m} 2)$. IMT lebih besar dari atau sama dengan 25 dianggap kelebihan berat badan, dan BMI lebih besar dari atau sama dengan 30 dianggap obesitas. Obesitas sangat terkait dengan resistensi insulin, yang bila digabungkan dengan defisiensi insulin relatif mengarah pada pengembangan diabetes mellitus tipe 2. Pada penelitian yang berbeda disebutkan bahwa diabetes mellitus dan obesitas merupakan factor risiko dari kanker pankreas (Alzaman and Ali, 2016; Başkan and Tan, 2017; Eibl et al., 2017) 
Hasil uji statistik pada tabel 2 diketahui bahwa ratarata LOS pasien diabetes mellitus yang PJK lebih tinggi yaitu 11.26 hari dengan variasi 7.64 hari, dibandingkan dengan LOS pasien diabetes mellitus tidak PJK yaitu 9.80 hari dengan variasi 7.77 hari. Hasil uji T didapatkan $\mathrm{p}$-value $=0.035$ berarti secara statistik ada perbedaan signifikan rata-rata LOS antara pasien diabetes mellitus yang PJK dengan yang tidak PJK.

PJK atau penyakit kardiovaskular merupakan penyebab kematian paling umum pada pasien diabetes mellitus tipe 2 karena PJK merupakan faktor risiko utama. Beban diabetes mellitus tipe 2 meningkat dimana pada tahun 20501 dari 3 individu AS mungkin menderita diabetes mellitus tipe 2, dan pasien dengan diabetes mellitus tipe 2 akan menjadi bagian yang semakin besar dari populasi penyakit kardiovaskular. Penggunaan terapi sangat terbukti mengurangi risiko penyakit kardiovaskular pada pasien diabetes mellitus tipe 2. Pedoman atau terapi untuk mengurangi risiko tersebut yaitu dengan memperhatikan gaya hidup (olahraga, nutrisi, dan manajemen berat badan) dan manajemen faktor risiko (tekanan darah, kolesterol dan lipid darah, kontrol glikemik, dan penggunaan aspirin) untuk pencegahan penyakit kardiovaskular pada pasien diabetes mellitus tipe 2. Gaya hidup dan manajemen faktor risiko yang tepat memiliki potensi secara signifikan untuk mengurangi beban penyakit kardiovaskular pada pasien diabetes mellitus tipe 2 (Newman et al., 2017). DM tipe 1 sangat terkait dengan peningkatan risiko infark miokard, gagal jantung, dan stroke iskemik. DM tipe 2 dikaitkan dengan peningkatan risiko infark miokard, stroke iskemik, gagal jantung, dan stenosis katup aorta (Larsson et al., 2018).

Hasil statistik pada tabel 2 diketahui bahwa ratarata LOS pasien diabetes mellitus yang stroke lebih tinggi yaitu 11.67 hari dengan variasi 8.73 hari, dibandingkan dengan LOS pasien diabetes mellitus tidak stroke yaitu 9.82 hari dengan variasi 7.70 hari. Hasil uji $\mathrm{T}$ didapatkan $\mathrm{p}$-value $=0.032$ berarti secara statistik ada perbedaan signifikan rata-rata LOS antara pasien diabetes mellitus yang stroke dengan yang tidak stroke.

Stroke secara luas diklasifikasikan sebagai iskemik atau hemoragik. Sekitar $85 \%$ dari stroke adalah iskemik, akibat dari arteri otak yang tersumbat dan menyebabkan kerusakan permanen dan kehilangan fungsi. Stroke hemoragik (15\% dari stroke) disebabkan oleh darah yang keluar dari arteri otak ke jaringan otak yang berdekatan, menghasilkan kerusakan permanen. Stroke hemoragik biasanya menyebabkan lebih banyak kerusakan daripada stroke iskemik. Ada faktor risiko stroke iskemik yang dapat dimodifikasi dan tidak dapat dimodifikasi. Usia, riwayat keluarga stroke, dan jenis kelamin adalah risiko yang tidak dapat dimodifikasi sedangkan factor risiko yang dapat dimodifikasi yaitu diabetes, hipertensi, kolesterol tinggi, penyakit jantung dan merokok (Alloubani, Saleh and Abdelhafiz, 2012; Rammal and Almekhlafi, 2016).

Ada perbedaan pola stroke antara pasien diabetes dengan yang tidak diabetes. Pasien dengan diabetes memiliki proporsi stroke iskemik yang lebih tinggi dibandingkan dengan stroke hemoragik, dan infark lakunar adalah jenis stroke yang paling umum. Hal ini disebabkan karena prevalensi penyakit mikrovaskular yang lebih tinggi dan koeksistensi hipertensi yang terlihat pada kelompok pasien ini (Tun et al., 2017).

Berdasarkan tabel di atas diketahui bahwa rata-rata LOS pasien diabetes mellitus yang TB Paru lebih tinggi yaitu 11.14 hari dengan variasi 11.08 hari, dibandingkan dengan LOS pasien diabetes mellitus tidak TB Paru yaitu 9.92 hari dengan variasi 7.74 hari. Hasil uji $\mathrm{T}$ didapatkan $\mathrm{p}$-value $=0.557$ berarti secara statistik tidak ada perbedaan signifikan ratarata LOS antara pasien diabetes mellitus yang TB Paru dengan yang tidak TB Paru.

Banyak hasil riset menemukan bahwa diabetes mellitus sering dikaitkan dengan peningkatan risiko TB. Penderita diabetes berisiko lebih tinggi terkena TB daripada mereka yang tidak menderita diabetes. Hubungan antara diabetes dan TB di negara maju sekitar 2.5 kali lebih, sedangkan di negara berkembang di mana prevalensi diabetes 2 kali lebih tinggi pada orang dengan TB daripada pada orang tanpa TB. Orang dengan diabetes mellitus menjadi target penting untuk intervensi seperti penemuan kasus aktif dan pengobatan TB. Sehingga upaya untuk mendiagnosis, mendeteksi, dan mengobati diabetes mellitus juga bisa dilakukan dengan pengendalian kasus TB (Jeon and Murray, 2008; Khalil and Ramadan, 2016).

Pria yang cenderung terkena diabetes mengalami penurunan fungsi paru-paru bertahun-tahun sebelum diagnosis, dibandingkan dengan pria yang tidak mengidap penyakit diabetes. Penurunan fungsi paru- 
paru ini tetap terjadi setelah terdiagnosis diabetes. Mekanisme yang terlibat dalam keadaan resisten insulin berkontribusi terhadap penurunan fungsi paru (Litonjua et al., 2005; I. et al., 2013; Zineldin, Hasan and Al-Adl, 2015).

\section{Simpulan}

Terdapat perbedaan signifikan rata-rata LOS antara pasien diabetes mellitus yang memiliki komplikasi hipertensi, neuropati, penyakit jantung koroner, dan stroke dengan yang tidak memiliki komplikasi penyakit tersebut. Sehingga perlu perawatan yang intensive oleh pihak rumah sakit terhadap pasien diabetes mellitus yang mengalami komplikasi tersebut agar tetap mempertahankan dan menjaga kualitas pelayanan dalam keadaan baik.

\section{Daftar Pustaka}

Alloubani, A., Saleh, A. and Abdelhafiz, I. (2012) 'Hypertension and diabetes mellitus as a predictive risk factors for stroke', Diabetes and Metabolic Syndrome: Clinical Research and Reviews, 12(4), pp. 577-584. doi: 10.1016/j.dsx.2018.03.009.

Alzaman, N. and Ali, A. (2016) 'Obesity and diabetes mellitus in the Arab world', Journal of Taibah University Medical Sciences. Elsevier Ltd, 11(4), pp. 301-309. doi: 10.1016/j. jtumed.2016.03.009.

Başkan, S. A. and Tan, M. (2017) 'Research of Type 2 Diabetes Patients' Problem Areas and Affecting Factors', Journal of Diabetes Mellitus, 07(03), pp. 175-183. doi: 10.4236/ jdm.2017.73014.

Cheung, B. M. Y. and Li, C. (2012) 'Diabetes and hypertension: Is there a common metabolic pathway?', Current Atherosclerosis Reports, 14(2), pp. 160-166. doi: 10.1007/s11883012-0227-2.

Donnan, P. T., Leese, G. P. and Morris, A. D. (2000) 'Hospitalizations for People With Type 1 and Type 2 Diabetes Compared With the Nondiabetic Population of Tayside, Scotland', Diabetes Care, 23(12). doi: 10.2337/diacare.27.10.2506.
Eibl, G. et al. (2017) 'Diabetes Mellitus and Obesity as Risk Factors for Pancreatic Cancer', Journal of the Academy of Nutrition and Dietetics. Elsevier Inc, 118(4), pp. 555-567. doi: 10.1016/j.jand.2017.07.005.

I., A. A. E.-A. et al. (2013) 'Pulmonary function changes in diabetic lung', Egyptian Journal of Chest Diseases and Tuberculosis. The Egyptian Society of Chest Diseases and Tuberculosis, 62(3), pp. 513-517. doi: 10.1016/j.ejcdt.2013.07.006.

International Diabetes Federation (2013) IDF Diabetes Atlas. 6th edn. Brussels: International Diabetes Federation.

Jeon, C. Y. and Murray, M. B. (2008) 'Diabetes mellitus increases the risk of active tuberculosis: A systematic review of 13 observational studies', PLoS Medicine, 5(7), pp. 1091-1101. doi: 10.1371/journal. pmed.0050152.

Kementerian Kesehatan RI (2012) Profil Kesehatan Indonesia 2011. Jakarta. doi: 10.1017/ CBO9781107415324.004.

Kementerian Kesehatan RI (2013) Riset Kesehatan Dasar 2013. Jakarta: Badan Penelitian dan Pengembangan Kesehatan.

Kementerian Kesehatan RI (2014) 'Waspada Diabetes; Eat well, Life well'. Jakarta: Kementrian Kesehatan RI.

Khalil, N. H. and Ramadan, R. A. (2016) 'Study of risk factors for pulmonary tuberculosis among diabetes mellitus patients', Egyptian Journal of Chest Diseases and Tuberculosis. The Egyptian Society of Chest Diseases and Tuberculosis, 65(4), pp. 817-823. doi: 10.1016/j.ejcdt.2016.05.009.

Larsson, S. C. et al. (2018) 'Type 1 and type 2 diabetes mellitus and incidence of seven cardiovascular diseases', International Journal of Cardiology. The Authors, 262, pp. 66-70. doi: 10.1016/j.ijcard.2018.03.099.

Litonjua, A. A. et al. (2005) 'Lung function in type 2 diabetes: The Normative Aging Study', Respiratory Medicine, 99(12), pp. 1583-1590. doi: 10.1016/j.rmed.2005.03.023. 
Muhammad, C. and Nazar, J. (2014) 'Diabetic nephropathy; principles of diagnosis and treatment of diabetic kidney disease', 3(1), pp. 15-20.

Nascimento, O. J. M. do, Pupe, C. C. B. and Cavalcanti, E. B. U. (2016) 'Diabetic neuropathy’, 17(Suppl 1), pp. 46-51. doi: 10.5935/1806-0013.20160047.

Newman, J. D. et al. (2017) 'Primary Prevention of Cardiovascular Disease in Diabetes Mellitus', Journal of the American College of Cardiology. Elsevier, 70(7), pp. 883-893. doi: 10.1016/j.jacc.2017.07.001.

NIDDK (2009) 'Diabetic Neuropathies: The Nerve Damage of Diabetes', in US Department of Health and Human Services (ed.). New York: National Institute of Health.

Nirantharakumar, K. et al. (2013) 'In-hospital mortality and length of stay in patients with diabetes having foot disease', Journal of Diabetes and its Complications. Elsevier Inc., 27(5), pp. 454-458. doi: 10.1016/j. jdiacomp.2013.05.003.

Notoatmodjo, S. (2003) Pengantar Pendidikan Kesehatan dan Ilmu Perilaku Kesehatan. Jakarta: Rineka Cipta.

Notoatmodjo, S. (2007) Kesehatan Masyarakat Ilmu dan Seni. Jakarta: Rhineka Cipta.
Rammal, S. A. and Almekhlafi, M. A. (2016) 'Diabetes mellitus and stroke in the Arab world', Journal of Taibah University Medical Sciences. Elsevier Ltd, 11(4), pp. 295-300. doi: 10.1016/j.jtumed.2016.05.001.

Silih, Y. (2012) Hubungan Antara Diabetes Melitus dengan Kejadian Hipertensi di Kecamatan Pontianak Selatan. Universitas Tanjungpura Pontianak.

Tun, N. N. et al. (2017) 'Diabetes mellitus and stroke: A clinical update', World Journal Diabetes, 9358(6).

Vujičić, B., Turk, T. and Crnčević-orlić, Ž. (2012) 'Diabetic Nephropathy'.

WHO (2017) 'Diabetes mellitus', WHO. World Health Organization.

World Health Organization (2017) Diabetes Fact Sheet. Available at: www.who.int/ mediacentre/factsheets/fs138en/ (Accessed: 20 February 2017).

Zineldin, M. A. F., Hasan, K. A. G. and Al-Adl, A. S. (2015) 'Respiratory function in type II diabetes mellitus', Egyptian Journal of Chest Diseases and Tuberculosis. The Egyptian Society of Chest Diseases and Tuberculosis, 64(1), pp. 219-223. doi: 10.1016/j.ejcdt.2014.08.008. 